\title{
A IMPORTÂNCIA DAS PROPOSTAS PEDAGÓGICAS PARA A EFETIVAÇÃO DE PRÁTICAS QUE RESPEITEM OS DIRETOS DAS CRIANÇAS.
}

Indira Aparecida Santana Aragão ${ }^{1}$, Gilza Maria Zauhy Garms ${ }^{2}$

${ }^{1}$ Aluna do curso de Pedagogia da Universidade Estadual Paulista - UNESP - Presidente Prudente. ${ }^{2}$ Docente do Departamento de Educação da Universidade Estadual Paulista - UNESP - Presidente Prudente E-mail: Indyra sa12@hotmail.com. Órgão de fomento: Pibic/CNPq.

\section{RESUMO}

O artigo constitui-se da análise das Propostas Pedagógicas da rede Municipal de Presidente Prudente, em face ao proposto pelos documentos oficiais que norteiam o atendimento da Educação Infantil no Brasil, com a intenção de contribuir para a construção de um currículo que respeite os direitos das crianças. A pesquisa se caracteriza como um estudo de caso e tem como instrumentos metodológicos a análise documental, questionário e observação. Os resultados são significativos, pois, apresentam um panorama da Educação Infantil da rede municipal de ensino, de modo a promover a tomada de consciência sobre a importância das Propostas Pedagógicas como um instrumento de garantia de qualidade das práticas na Educação Infantil.

Palavras Chave: Proposta Pedagógica, Educação Infantil, Direitos das crianças, Prática docente.

\section{INTRODUÇÃO}

A pesquisa intitulada Formação Profissional para a docência na Educação Infantil: contribuições a partir da análise de propostas pedagógicas/curriculares praticadas em creches e pré-escola da rede municipal de presidente têm as propostas pedagógicas/curriculares como objeto de sua pesquisa, pois acreditamos que as propostas pedagógicas são orientadoras das ações práticas na instituição e que através delas se define o que se pretende desenvolver com as crianças, as aprendizagens que ser trabalhar, construindo assim, práticas educacionais que sejam comprometidas com os direitos das crianças.

\footnotetext{
"As propostas pedagógicas para as instituições de educação infantil devem promover em suas práticas de educação e cuidados, a integração entre os aspectos físicos, emocionais, afetivos, cognitivo/linguísticos e sociais da criança, entendendo que ela é um ser total, completo e indivisível". (Diretrizes Curriculares Nacionais para a Educação Infantil 1998, p.11).
}

Esta pesquisa tem como principal objetivo analisar e diagnosticar as propostas pedagógicas da Rede Municipal de Presidente Prudente, em face ao proposto pelos documentos oficiais que regulamentam o trabalho da Educação Infantil no Brasil.

Desta forma propomos aprofundar a compreensão a respeito da multiplicidade e heterogeneidade das propostas pedagógicas e das práticas realizadas nas instituições de educação 
infantil da Rede Municipal de Presidente Prudente, de modo a contribuir com a construção de um currículo que possibilite um atendimento de qualidade as crianças pequenas.

\section{METODOLOGIA}

A pesquisa qualitativa intitulada Formação Profissional para a docência na Educação Infantil: contribuições a partir da análise de propostas pedagógicas/curriculares praticadas em creches e pré-escola da rede municipal de Presidente Prudente se caracteriza como descritiva e analítica, tendo como método de coleta de dados, a análise documental e a observação, visto que pretende registrar os caminhos pelos quais os profissionais se utilizam para a elaboração e implementação de suas práticas.

Desta forma, enquadra-se também na modalidade estudo de caso, uma das formas que pode assumir a pesquisa qualitativa, posto que é o estudo de um caso - as creches e pré-escolas da Rede Municipal de Presidente Prudente - bem delimitado, que mesmo sendo similar a outros é ao mesmo tempo diferente, pois tem características que o tornam único. (LUDKE; ANDRE, 1986).

O universo da investigação é composto pelas escolas municipais de Educação Infantil, num total de 42 , tendo as seguintes modalidades:

- Creche: 6 Unidades;

- Pré-Escola: 1 Unidade

- Creche e Pré-Escola: 11 Unidades

- Creche, Pré-Escola e Ensino Fundamental: 6 Unidades

- Pré-Escola e Ensino Fundamental: 13 Unidades

- Creches Filantrópicas (Creche E Pré-Escola): 5 Unidades

Para a realização da pesquisa foram selecionadas 6 escolas representando as seguintes modalidades:

- $\quad$ Creche: EM WM

- $\quad$ Pré-escola: EM JB

- $\quad$ Creche e Pré-escola: EM EMD

- $\quad$ Creche, Pré-escola e Ensino Fundamental: EM OA

- $\quad$ Pré-escola e Ensino Fundamental: EM ERR

- $\quad$ Creches filantrópicas: Creche AFB

Cada escola mencionada teve seu Plano Diretor analisado, bem como para elucidar questões que não ficaram claras nas análises dos Planos Diretores, foi aplicado um questionário 
para cada instituição onde se procurou que pelo menos um professor e um educador infantil respondesse o mesmo, o critério de seleção dos profissionais foi o tempo de serviço. Posteriormente á aplicação de questionário realizamos observações nas instituições analisadas com o objetivo de confronta-las com o proposto nos Planos Diretores. Esta pesquisa foi avaliada e aprovada antes de sua realização pelo comitê de ética em pesquisa da FCT-UNESP de Presidente Prudente com o protocolo de número 03/2011.

Por se tratar de uma pesquisa ampla, optamos por apresentar neste artigo os dados que consideramos mais significativos para refletir o papel da Educação Infantil, considerando a importância das propostas pedagógicas como elemento norteador das práticas realizadas e que reflete a concepção de criança e educação que queremos.

\section{RESULTADOS}

As propostas pedagógicas denominadas pela SEDUC- Secretaria de Educação do Município de Presidente Prudente como Planos Diretores não registram os responsáveis por sua formulação, ou seja, não é possível identificar quem participou da elaboração dos Planos Diretores, nas análises realizadas fica exposto a desvalorização do processo de construção coletiva das propostas pedagógicas.

Os dados dos questionários nos apontam que as discussões para elaboração das propostas foram feitas durantes as reuniões de HTPC (Horário de Trabalho Pedagógico Coletivo), contando apenas com a participação de alguns professores, e não envolvendo toda comunidade escolar.

A gestão democrática da proposta curricular deve contar na sua elaboração, acompanhamento e avaliação do Projeto Político Pedagógico da unidade educacional com a participação coletiva de professoras e professores, demais profissionais da instituição, famílias, comunidade e das crianças, sempre que possível e a sua maneira. (Diretrizes Curriculares Nacionais para a Educação Infantil. 2009 p.06).

A construção coletiva da proposta pedagógica é de grande relevância para a comunidade escolar, conforme afirma (Souza; Corrêa, 2002, p.55): “[...] o projeto pedagógico possui uma intencionalidade explícita, visto que deve partir da discussão coletiva dos problemas da escola e da busca de solução para os mesmos [...]". Desta maneira ao ser elaborado de forma coletiva todos podem ser ouvidos, e com isso pode-se buscar a melhoria na qualidade do processo de ensino e aprendizagem. 
A proposta pedagógica é instrumento de grande relevância para se garantir um trabalho de qualidade na instituição, é nela que se estabelecem os objetivos, as metas que se pretende atingir, as aprendizagens que se deseja promover com as crianças que são educadas e cuidadas.

O documento analisado é construído através de um modelo que contem as seguintes divisões: Introdução, Objetivo, Identificação e Caracterização da UE, Descrição da realidade escolar, Diagnostico do Processo de Ensino Aprendizagem, Recursos necessários para implementação das ações, projetos especiais, Critérios para acompanhamento, Controle e Avaliação do plano diretor, Bibliografia e Anexos. De acordo com a especificidade da divisão há subdivisões. Em alguns há epigrafe e sumário.

De maneira geral, os Planos Diretores não apresentam qual a fundamentação teórica que embasou a sua construção. Dentre as seis escolas analisadas, apenas uma cita alguns autores e outra escola descreve os documentos legais entre eles: Lei de Diretrizes e Bases da Educação Nacional, Referenciais Curriculares Nacionais para a Educação Infantil, Diretrizes Curriculares Nacionais para a Educação Infantil e Indicadores de Qualidade na Educação Infantil. Porém muitas ações práticas e atitudes realizadas pelos profissionais que atuam nas instituições precisam ser revistas, visto que se utiliza de práticas tradicionais, como por exemplo, salas organizadas em fileiras como no ensino fundamental, onde o professor é o centro do processo e não a criança.

Os Planos Diretores privilegiam as rotinas como forma de organização do trabalho na educação infantil, e apresentam de um modo geral, os momentos que devem conter uma rotina de educação infantil, sendo eles: acolhida e despedida; roda de conversa, histórias e músicas; planejamento e avaliação; alimentação; repouso; trabalho coletivo; trabalho diversificado e individual; projetos; recreação; passeios.

Ao observar as instituições percebemos a rotina descrita no Plano Diretor é executada de uma forma rígida tomando conta das brincadeiras e atividades que tornem a criança centro do processo educativo, todas as instituições seguem um mesmo padrão de rotina, o que as diferencia é a idade da criança e o período de permanência da mesma na instituição.

As rotinas são maneiras de organizar o espaço e o tempo da instituição de Educação Infantil, "é possível afirmar que elas sintetizam o projeto pedagógico das instituições e apresentam a proposta de ação educativa dos profissionais". (BARBOSA, 2006, p.35). Desta forma consideramos que a rotina é de extrema importância para o desenvolvimento das ações dos educadores, tanto na creche como na pré-escola, a organização do tempo do espaço e das 
atividades são elementos que se relacionam e tornam a educação e o cuidado das crianças pequenas com intencionalidade.

De acordo com (BARBOSA, 2006, p.177) "as rotinas estão presentes em quase todas as propostas pedagógicas para a educação infantil". Elas são de grande importância para a construção de um currículo que respeite as especificidades das crianças, considerando o contexto de cada instituição.

As Instituições de Educação Infantil precisam organizar um cotidiano de situações agradáveis, estimulantes, que desafiem o que cada criança e seu grupo de crianças já sabem sem ameaçar sua autoestima nem promover competitividade, ampliando as possibilidades infantis de cuida e ser cuidada, de se expressar, comunicar e criar, de organizar pensamentos e ideias, de conviver, brincar e trabalhar em grupo, de ter iniciativa e buscar soluções para os problemas e conflitos que se apresentam as mais diferentes idades, e lhes possibilitem apropriar-se de diferentes idades, e Ihes possibilitem apropriar-se de diferentes linguagens e saberes que circulam em nossa sociedade, selecionados pelo valor formativo que possuem em relação aos objetivos definidos em seu Projeto Político Pedagógico. (Revisão das Diretrizes Curriculares Nacionais para a Educação Infantil, 2009, p.9).

Como aponta a Revisão das Diretrizes Curriculares Nacionais para a Educação Infantil (2009) a organização do cotidiano, precisa respeitar as especificidades da infância, os objetivos do projeto pedagógico devem estar claros de forma a contribuir com o trabalho do professor.

O currículo é organizado por eixos, áreas de conhecimento assim distribuídas: identidade e autonomia, movimento, música, artes visuais, linguagem oral e escrita, natureza e sociedade e matemática. São apresentados em tabelas com a definição de cada eixo, conteúdos, objetivos e suas implicações educacionais por faixa etária.

Os eixos citados nos Planos Diretores são fundamentados nos Referenciais Curriculares Nacionais para a Educação Infantil (1998) - RCNEl, documento que subsidia o que e como trabalhar os conteúdos com as crianças de a 0 a 3 - creche - e dos 4 aos 6 anos - pré-escola, buscando qualificá-la. Podemos considerar isto como um fator positivo, pois as escolas conhecem e estão utilizando um subsídio teórico e prático na organização do cotidiano nas instituições de Educação Infantil.

Os Planos diretores analisados não apresentam nenhuma proposta de articulação entre os níveis de ensino. Contudo, quando questionadas sobre como pensam a articulação da Educação Infantil com as séries iniciais do Ensino Fundamental, algumas unidades afirmam manter contato 
com a escola de ensino fundamental mais próxima a fim de garantir que seus alunos ao final da Educação Infantil sejam transferidos para lá, dando continuidade aos seus estudos.

A Revisão das Diretrizes menciona que:

$\mathrm{Na}$ busca de garantir um olhar continuo sobre os processos vivenciados pela criança, devem ser criadas estratégias adequadas aos diferentes momentos de transição por elas vividos. As instituições de Educação Infantil devem assim:

[...] d) prever formas de articulação entre os docentes da Educação Infantil e do Ensino Fundamental (encontros, visitas, reuniões) e providenciar instrumentos de registro - portfólios de turmas, relatórios de avaliação do trabalho pedagógico, documentação da freqüência e das realizações alcançadas pelas crianças - que permitam aos docentes do Ensino Fundamental conhecer os processos de aprendizagem vivenciados na Educação Infantil, em especial na pré-escola e as condições em que eles se deram, independentemente dessa transição ser feita no interior de uma mesma instituição ou entre instituições, para assegurar às crianças a continuidade de seus processos peculiares de desenvolvimento e a concretização de seu direito à educação. (BRASIL, 2009, p.17).

Contudo podemos concluir que a maioria dos profissionais desconhece essa articulação, e por não compreenderem sua importância deixam-na de lado, e não á consideram como um instrumento importante no desenvolvimento da aprendizagem da criança.

O que mais nos chamou a atenção é o fato de que a proposta pedagógica da instituição não é considerada como um instrumento relevante na construção das práticas dos professores que muitas vezes não participam de sua elaboração e nem conhecem este documento.

Os documentos oficiais nos apontam que as propostas pedagógicas são documentos que norteiam e subsidiam o trabalho nas instituições de creche e pré-escola, conforme afirma as Diretrizes Curriculares Nacionais para Educação Infantil (2009).

A proposta pedagógica, ou projeto pedagógico, é o plano orientador das ações na instituição e define as metas que se pretende para o desenvolvimento dos meninos e meninas que nela são educados e cuidados, as aprendizagens que se quer promovidas. Na sua execução, a instituição de educação infantil organiza seu currículo, que pode ser entendido como as práticas educacionais organizadas em torno do conhecimento e em meio ás relações sociais que se travam nos espaços institucionais, e que afetam a construção das identidades das crianças. (Diretrizes Curriculares Nacionais para a educação infantil, 2009, p.06). 
“O trabalho coletivo é, portanto, ponto de partida e de chegada de um projeto político pedagógico e não pode ficar congelado - sob pena de se tornar autoritário - como se estivesse pronto para ser aplicado". (Kramer, 2008, p. 73).

Desta forma, concluímos que é preciso provocar nos profissionais a tomada de consciência sobre a importância das Propostas Pedagógicas, pois as mesmas traduzem a concepção de criança e de aprendizagem que queremos oferecer a elas.

\section{DISCUSSÃO}

Os dados apresentados são importantes para repensar o papel da educação infantil, apesar das dificuldades apresentadas os Planos Diretores trazem suas fundamentações articuladas com o proposto pelos documentos nacionais que norteiam o atendimento da Educação Infantil. Porém as práticas realizadas nas instituições necessitam continuamente de reflexão, visto que ainda se utilizam de práticas que não consideram a criança como centro do processo educativo.

As Diretrizes Curriculares Nacionais afirmam em seu artigo 4을

As propostas pedagógicas da Educação Infantil deverão considerar que a criança, centro do planejamento curricular, é sujeito histórico e de direitos, que nas interações, relações e práticas que vivencia, constrói sua identidade pessoal e coletiva, brinca, imagina, fantasia, deseja, aprende, observa, experimenta, narra, questiona e constrói sentidos sobre a natureza e a sociedade, produzindo cultura. (Diretrizes Curriculares Nacionais para a Educação Infantil, 2009, p.01).

O Projeto Político Pedagógico é um instrumento de decisão política, onde estão explicitados os objetivos, recursos e estratégias de trabalho a serem realizados com as crianças.

"[...] todo projeto de educação infantil deve afirmar a igualdade, entendendo que as crianças - também as de zero a seis anos - são cidadãos de direitos, têm diferenças que precisam ser reconhecidas e pertencem a diversas classes sociais, vivendo na maioria das vezes uma desigualdade que precisa ser superada". (Kramer, 2008, p.55).

Os resultados apontados permitem inferir há existência de uma forte concepção ambientalista que acredita que o desenvolvimento é totalmente dependente do que o meio-sócio cultural oferecer a cada criança e que a aprendizagem ocorre através de programas de associações, condicionamento e reforçamento. Nesta perspectiva, a criança não é considerada como principal sujeito da educação infantil, deste modo é preciso ressignificar as práticas 
existentes, repensá-las e organizá-las de modo que contribuam para o desenvolvimento integral das crianças.

\section{CONCLUSÃO}

Os resultados apresentados são importantes no sentido que buscam realizar um panorama da Educação Infantil, oferecida pela rede municipal de ensino.

As análises realizadas procuram promover nos profissionais a tomada de consciência sobre a importância das Propostas Pedagógicas como um instrumento de garantia da qualidade na Educação Infantil, conforme afirma as Diretrizes Curriculares Nacionais para Educação Infantil (2009).

A proposta pedagógica, ou projeto pedagógico, é o plano orientador das ações na instituição e define as metas que se pretende para o desenvolvimento dos meninos e meninas que nela são educados e cuidados, as aprendizagens que se quer promovidos. Na sua execução, a instituição de educação infantil organiza seu currículo, que pode ser entendido como as práticas educacionais organizadas em torno do conhecimento e em meio ás relações sociais que se travam nos espaços institucionais, e que afetam a construção das identidades das crianças. (Diretrizes Curriculares Nacionais para a educação infantil, 2009, p.06).

Deste modo as Propostas Pedagógicas traduzem a concepção de criança que temos sobre os nossos meninos e meninas na Educação Infantil, seu papel é oferecer subsídios para os profissionais e possibilitar o diálogo entre a teoria e a prática por meio da reflexão-ação-reflexão, tirando as leis do papel e atribuindo um novo sentido ao trabalho docente.

As propostas pedagógicas das instituições devem oferecer subsídios para os profissionais que atuam na Educação Infantil, para favorecer a desconstrução de crenças arraigadas no ideário pedagógico dos professores. Um dos possíveis caminhos é dar condições para provocar o dialogo entre a teoria e a prática, que permita avanços no modo de compreender como a criança aprende e se desenvolve. A tomada de consciência sobre o fazer acena com a possibilidade por meio da ação-reflexão-ação "tirar as leis e as teorias do papel" aproximando cada vez mais as conquistas legais e os avanços teóricos sobre a criança da prática manifesta dos professores, dado o caráter ativo e determinante das pessoas que com elas atuam. Evidencia-se, portanto, a necessidade de uma ação educativa de qualidade no período correspondente à Educação Infantil. 


\section{REFERÊNCIAS}

BARBOSA, Maria Carmem Silveira. Por Amor e por Força: Rotinas na Educação Infantil. Porto Alegre: Artmed, 2006.

Lei de Diretrizes e Bases da Educação Nacional. Lei n. 9394 promulgada em 20 de dezembro de 1996. São Paulo: Roma Victor ed., 2007.

. Resolução CEB no 022 de 17 de Dezembro de 1998. Fixa as Diretrizes Curriculares Nacionais para Educação Infantil. $\overline{20 / 2009 .}$

. Revisão das Diretrizes Curriculares Nacionais para a Educação Infantil. Parecer CNE/CEB no

Ministério da Educação. Secretaria de Educação Básica. Política Nacional de Educação Infantil: pelo direito das crianças de zero a seis anos de idade à educação. Brasília: MEC/SEB, 2006.

KRAMER, S. Direitos da criança e projeto político pedagógico de educação infantil. In: BAZILO, L. C.; KRAMER, S. (orgs.).Infância, Educação e Direitos Humanos. São Paulo: Cortez Editora, 2008.

LUDKE, M.; ANDRÉ, M. E. D. A. Pesquisa em educação: abordagens qualitativas. São Paulo: EPU, 1986.

SOUSA, José V; CORRÊA, Juliane. Projeto Pedagógico: a autonomia construída no cotidiano da escola In: DAVIS, Claudia. (et al). Gestão da escola: desafios a enfrentar. Rio de Janeiro: DP\&A, 2002. 